\title{
DESIGN AND FABRICATION OF SOLAR BASED EVAPORATIVE COOLING AIR CONDITIONER
}

\author{
Ashwani Sharma ${ }^{1}$, Tushar Saxena ${ }^{2}$, Priyank Pant ${ }^{3}$, Shantanu Gandhi ${ }^{4}$ \\ ${ }^{1}$ Assistant Professor, Mechanical and Automation Department, Amity University Lucknow \\ ${ }^{2,3,4}$ Mechanical and Automation Department, Amity University Lucknow
}

\begin{abstract}
This paper describes design and fabrication of air conditioning system that uses solar evaporation to obtain cooling. The basic idea was to design a system that is affordable, consumes less energy and gives the same effect as that of the conventional air conditioner. This system provides satisfactory results. The only disadvantage observed; is long time required to get the desired cooling effect.
\end{abstract}

Keywords: Solar Evaporation, Evaporative Cooling, Water Level Sensor

\section{INTRODUCTION}

Air conditioner (AC) used for air conditioning consumes a large amount of power. In addition, the cost and power consumption bills of $\mathrm{AC}$ is not affordable by most of the people in our country. Research work is going on comfort air conditioner and air cooler in order to make it affordable and reduce power consumption. These researches are basically the improvement in the existing technology; however, less attention has been given to price factor. $\mathrm{AC}$ is considered luxury in our country People cannot afford to buy and run this machine when temperature is very high in summer. Ceiling fan and coolers are the only option left hence an immediate requirement to make it affordable for each is the need of the hour.

This paper conceptualizes an alternative design method called solar evaporation cooling system. It is a low cost, affordable and homemade system produces satisfactory result. This low coast system can have wide range of applications in urban as well as rural areas due to less power consumption and easy manufacturing with easily and naturally available resources.

\section{PRESENT TECHNOLOGY AVAILABLE}

Many brands produce comfort machineries/ equipment across the globe. There are two types of technology used now days

(i) Evaporation of refrigerant in the closed tube and then creation of high pressure and low pressure conditions by compressor and expansion device. This type of air conditioner (AC) gives the desired comfort condition and temperature with control mechanism. However the capital investment and running cost due to high power consumption is high which makes it not very affordable in our country and a luxury.

(ii) Evaporation of water by sprinkler and with pump on hay pads and drawing air by using an induced fan, which draws the air through the wet hey pads.
This is known as Air cooler/ dessert air cooler.

Air cooler is better option as compared to a ceiling fan due to its ability to provide better cooling however there is no humidity controller and also no feedback mechanism through which $\mathrm{d}$ specific desired temperature can be achieved. It also accelerates microbiological growth and so further increases health issues and a moist and humid environment also. Capital and running cost of Air cooler is lesser than Air conditioner due to lower price and also lower power consumption.

This paper conceptualized a new design called solar evaporative air conditioner, which fill the gap of humidity and cost issues.

\section{SYSTEM DESCRIPTION}

In this system, a cooling unit is installed outside the room, which consists of an earthen pot. This earthen pot has coiled copper tube, which is then covered with a layer of clay. The clay is actually a mixture of clay and mud. The clay is made wet with water. When water evaporates it absorb latent heat and there by produces cooling effect. This cooling effect is given to the copper tubes, which in turn gives it to water flowing in the tubes. This water is then pumped to copper coil (Heat Exchanger) attached in front side of the fan of air cooler. When water is made to flow through the coil it condenses the moisture and also decreases the temperature of the air coming out of the cooler to a considerable limit and cooling and partial dehumidification is obtained. The water is continuously circulated to obtain desired cooling effect. A feedback mechanism is also used to sense the water level in outdoor unit. If the level is less than the desired level, it automatically pumps the water in the outdoor unit. 


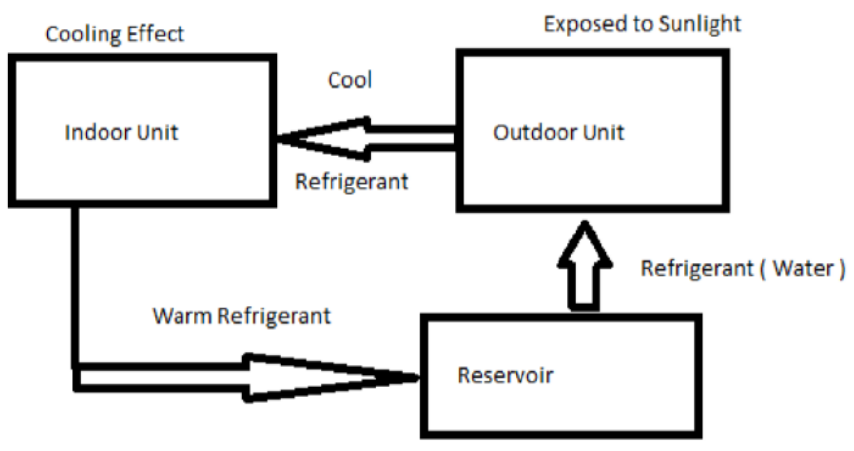

Figure 1: Layout of Solar evaporation Air Conditioner

\section{FABRICATION}

The primary components of the refrigeration system are:

\section{a) Cooling Unit}

\section{(i) Indoor Unit}

Indoor system comprises of fan which is used as a source for dissipating the cooling effect in the closed environment. It also consists of a pump which is used to circulate the refrigerant throughout the coil. The cooling effect produced will be because of the result of the outdoor unit and the indoor unit. The indoor unit successfully dissipates the cooling affect and circulates the refrigerant throughout the system which due to continuous circulation within the system produces better cooling effect which means after successful running of the project unit for few hours the cooling effect produced by the system is increased and a better cooling and functioning can be obtained.

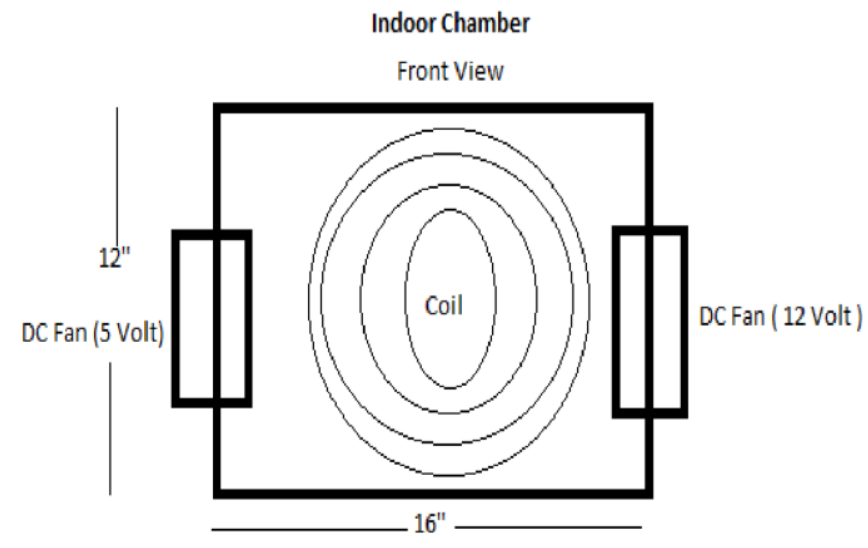

Figure 2: Indoor unit of the system

\section{(ii) Outdoor Unit}

It is the unit which is exposed to the sunlight and we have introduced clay which is actually a mixture of clay and sand which is spread over a surface so that we can improve the cooling effect by maximizing the surface exposed to the sunlight. The clay is hydrated using a sensor based pump. The pump hydrates the clay mixture and at the same time due to evaporation the cooling effect is produced in the coil which is further used to cool the coolant and then used in the indoor system for the cooling effect.

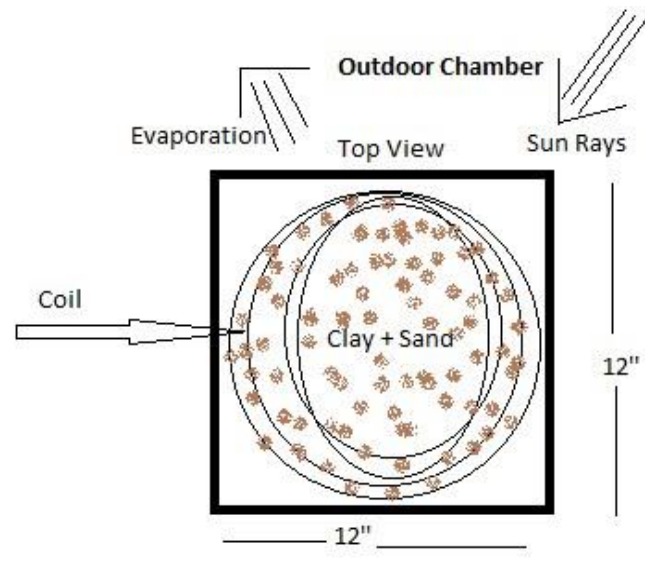

Figure 3 : Outdoor unit of the system

\section{b) Pump}

It is use to circulate the working fluid i.e water within the system. The cooling effect is produced only with the help of circulating of water so pump is one of the main component of our system also due to more and more circulation of water within the system the cooling effect is increased.

\section{c) Water Level Sensor}

A feedback mechanism is also used that sense water level in outdoor unit. If the level is less than the desired level, it automatically pumps the water in the outdoor unit to maintain an optimum and function able level of water in the clay. An optimum level of moisture in the clay is required to maintain the cooling by the system.

\section{PERFORMANCE ANALYSIS}

The output of evaporative AC is lower room temperature is achieved.

This is achieved by testing and working of project for 3 hours in a closed chamber. The dimensions of the chamber is $26 " x 26 " x 28 "$.

Dry bulb temperature and wet bulb temperature is measured using sling psychrometer

Readings: DBT and WBT is obtained from experimental readings

\section{Initial Condition:}

Ambient temperature: $41^{\circ} \mathrm{C}$

Table 1: Dry bulb and Wet bulb temperature along with humidity

\begin{tabular}{|l|l|l|l|}
\hline $\begin{array}{l}\text { TIME } \\
(\mathrm{MIN})\end{array}$ & $\begin{array}{l}\text { DRY BULB } \\
\text { TEMPERATURE } \\
(\mathrm{C})\end{array}$ & $\begin{array}{l}\text { WET BULB } \\
\text { TEMPERATURE } \\
(\mathrm{C})\end{array}$ & $\begin{array}{l}\text { HUMIDITY } \\
(\%)\end{array}$ \\
\hline 00 & 37 & 30 & 59.9 \\
\hline 30 & 36 & 29 & 59.3 \\
\hline 60 & 35.6 & 28.7 & 59.5 \\
\hline 90 & 35.2 & 28.4 & 59.8 \\
\hline 120 & 35.0 & 28 & 58.6 \\
\hline 150 & 34.9 & 28 & 59.1 \\
\hline 180 & 34.8 & 27.8 & 58.5 \\
\hline
\end{tabular}




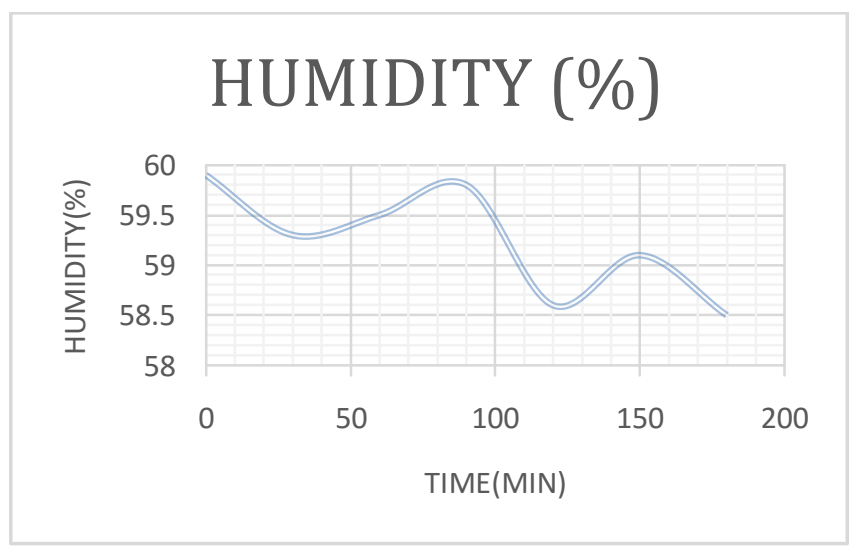

\section{Explanation of the Graph-}

The humidity is measured using psychrometric chart via dry bulb temperature and wet bulb temperature. However, the graph attends by the reading has variation but if the unit is run for more time a constant decrease in humidity can be attend.

\section{CONCLUSION}

Air cooler gives the cool and humid air. Humidity of air can be absorbed by cooling coil. Which is a cheap and effective design conceptualization in comfort application. Solar Evaporative air conditioner can be fabricated at home with naturally available resources and without spending much with low operation cost.

Further modifications can be done to improve the performance of solar evaporative air conditioning system which can produce even more effective cooling systems.

\section{REFERENCES}

[1] O. Amer, R. Boukhanouf, H.G. Ibrahin,"A Review of Evaporative Cooling Technologies", International Journal of Environmental Science and Development, Vol. 6, No. 2, February 2015, pages. 111-117

[2] Rajesh Maurya, Dr. NitinShrivastava, VipinShrivastava, "Performance and Analysis of an Evaporative Cooling System: A Review “, International Journal of Scientific \& Engineering Research, Volume 5, Issue 10,October2014

[3] R.S. Khurmi and J.K. Gupta, "Refrigeration and Air Conditioning", S. Chand Publication House, pp 198212(2014)

[4] B.L. Thakor.," Economical Evaporative Air Conditioner for Equatorial and Tropical Regions", International Journal on Recent and Innovation Trends in Computing and Communication, Volume: 3 Issue: 1, pp $11-13$ (2015)

[5] R.B. Lokapure, J.D. Joshi, "Energy conservation through roof surface evaporative cooling for air conditioning system", International Journal of Scientific and Research Publications, Volume 2, Issue 6, June 2012

[6] http://www.holsoft.nl/physics/rhcalc1.html 